Resumo

\title{
Avaliação do perfil dietético dos atletas da equipe de futebol do Exército Brasileiro
}

Rafael Carreiro Lermen Bsci, Cláudia Meirelles PhD

Introdução: O perfil dietético de jogadores de futebol, amadores ou profissionais, tem sido bastante estudado, contudo poucas pesquisas abordam a avaliação nutricional de atletas militares.

Objetivo: Avaliar o perfil dietético dos atletas da equipe de futebol do Exército Brasileiro.

Métodos: A amostra foi composta por 18 atletas com idade média de 27,9 $\pm 5,2$. Para o diagnóstico do estado nutricional, foram analisados a adequação de carboidratos (CHO), de lipídios (LIP) e de proteínas (PTN) por meio do registro alimentar de três dias, avaliados com o software NutWin e comparados as recomendações dietéticas do posicionamento em conjunto do American Dietetic Association, Dietitians of Canada and American College of Sports Medicine (2009). Resultados: A distribuição percentual de macronutrientes em relação à ingestão energética total se encontrou dentro das recomendações, sendo de $54,6 \pm 6,7 \%$; $20,7 \pm 4,4 \%$ e $24,8 \pm 5,1 \%$, do valor energético total diário (2797 $\pm 530 \mathrm{kcal}$ ), respectivamente, para CHO, PTN e LIP. Contudo, ao se considerar os valores em $\mathrm{g} / \mathrm{kg}$ de massa corporal, a ingestão de CHO mostrou-se abaixo das recomendações $(5,0 \pm 1,3 \mathrm{~g} / \mathrm{kg} / \mathrm{d})$. Já a ingestão de PTN encontrou-se acima das recomendações $(1,9 \pm 0,6 \mathrm{~g} / \mathrm{kg} / \mathrm{d})$.

Conclusão: Há indícios que os atletas avaliados apresentaram uma inadequada ingestão de macronutrientes frente às recomendações nutricionais para sua modalidade esportiva. Portanto, evidencia-se a necessidade de novos estudos visando monitorar os hábitos alimentares dos jogadores militares de futebol. 